\title{
Exopolysaccharide from Lactobacillus plantarum LRCC5310 offers protection against rotavirus-induced diarrhea and regulates inflammatory response
}

\author{
Kiyoung Kim, ${ }^{* 1}$ Gyeonghweon Lee, $\dagger \ddagger^{1}$ Hien Dang Thanh, ${ }^{*}$ Jong-Hwa Kim, ${ }^{*}$ Maytiya Konkit, ${ }^{*}$ Seokmin Yoon, $\ddagger$ \\ Miri Park, $\ddagger$ Siyoung Yang, Eunsup Park, $§$ and Wonyong Kim*2 \\ *Department of Microbiology, College of Medicine, Chung-Ang University, Seoul 06974, Republic of Korea \\ †Division of Biotechnology, College of Life Sciences, Korea University, Seoul 02841, Republic of Korea \\ fLotte R\&D Center, Seoul 07594, Republic of Korea \\ $\S$ Department of Pathology, College of Medicine, Chung-Ang University, Seoul 06974, Republic of Korea
}

\begin{abstract}
We aimed to determine the effects of Lactobacillus strains against rotaviral infections. Rotaviruses are the major causative agent of acute gastroenteritis in infants and children worldwide. However, to date, no specific antiviral drugs for the treatment of rotavirus infection have been developed. We identified 263 Lactobacillus strains from 35 samples of the traditional Korean fermented vegetable food kimchi. Among them, Lactobacillus plantarum LRCC5310, more specifically the exopolysaccharides produced by these cells, were shown to have an antiviral effect against human rotavirus Wa strain in vitro. In vivo, the oral administration of exopolysaccharides for $2 \mathrm{~d}$ before and $5 \mathrm{~d}$ after mouse infection with the murine rotavirus epidemic diarrhea of infant mice strain led to a decrease in the duration of diarrhea and viral shedding and prevented the destruction of enteric epithelium integrity in the infected mice. We demonstrated here that the exopolysaccharides extracted from L. plantarum LRCC5310 can be used for the effective control of rotavirus infection.
\end{abstract}

Key words: Lactobacillus plantarum, rotavirus, diarrhea, exopolysaccharide

\section{INTRODUCTION}

Rotavirus is the leading cause of severe diarrhea in newborns and young children worldwide, and it was estimated to be responsible for approximately over 453,000 rotavirus deaths in children annually (Tate et al., 2012). Two live, oral, attenuated rotavirus vaccines [Rotarix (GlaxoSmithKline, Brentford, UK) and RotaTeq (Merck, Kenilworth, NJ)] were recommended

Received November 18, 2017.

Accepted February 23, 2018.

${ }^{1}$ These authors contributed equally to this work.

${ }^{2}$ Corresponding author: kimwy@cau.ac.kr by the World Health Organization in 2009 (Tate et al. 2016); these vaccines were shown to be highly efficient against severe rotavirus diarrhea, ranging from a 45 to $90 \%$ success rate (Velázquez et al., 2017). However, unusual and vaccine-derived reassortant rotavirus strains have recently been reported in the feces of vaccinated infants, and these were cases of sibling transmission or co-infection with human and animal rotavirus strains (Hemming and Vesikari, 2014; Than et al., 2015; Jeong et al., 2016). Therefore, novel approaches to the treatment and prevention of the infectious diarrhea caused by rotavirus are required.

Recently, exopolysaccharides (EPS) synthesized by lactic acid bacteria (LAB) attracted much research attention in the field of probiotics, as they are natural biopolymers (Patel and Prajapat, 2013). Exopolysaccharides are large, structurally diverse polysaccharides that permeate the extracellular environment in the form of capsules or biofilms (Kleerebezem et al., 2010), and these molecules help bacteria to survive extreme environmental conditions (Nichols et al., 2005). Furthermore, they have potential health benefits, such as pathogen growth inhibition (Patten and Laws, 2015), antiviral activity (Gugliandolo et al., 2014), and immune stimulation (Ciszek-Lenda et al., 2011; HidalgoCantabrana et al., 2012; Inturri et al., 2017), together with the ability to adhere to the cell surface (Caggianiello et al., 2016).

Lactobacillus plantarum is a bacterium with a generally-recognized-as-safe status, as determined by the US Food and Drug Administration, found in various habitats, such as vegetables, meat, sausages, and cheese (Tanganurat et al., 2009). This bacterium is generally used in food industry applications, including in yogurt, fermented vegetables, and beverages (Brinques and Ayub, 2011). Many potential health benefits of $L$. plantarum have been reported, such as effects on cholesterol, diarrhea, and irritable bowel syndrome (Barreto et al., 2014). After growing in glucose or sucrose, L. plantarum strains can produce EPS (Ismail and 
Nampoothiri, 2010), and the reported benefits include antioxidant (Zhang et al., 2013), antitumor (Shin et al., 2016), anti-inflammatory activity (Toshimitsu et al., 2017), as well as antiviral activity against herpes simplex virus (Matsusaki et al., 2016); however, no effects against rotavirus have been reported previously.

Kimchi is a Korean traditional fermented vegetable food, known for its beneficial effects on human health, including its antitumor (Kim et al., 2014b; Kwak et al., 2014), antimicrobial (Chang and Chang, 2011), antioxidative (Kim et al., 2014a; Xing et al., 2015), antiobesity (Lee et al., 2015), and immune system-stimulating activities (Lee et al., 2014). The fermentation of kimchi is induced by using plant microflora under a variety of conditions, including different bacteria, such as Lactobacillus and Leuconostoc, as well as yeast (Chang et al., 2010). Among them, L. plantarum is the predominantly used bacterium at the middle and later stages of fermentation due to the high acid production, resulting in the acidification of kimchi (Lee et al., 2016).

To date, many studies discussing the processing of kimchi have been conducted, but further analysis of the beneficial functions of the kimchi-isolated LAB should be performed (Khan and Kang, 2016). Therefore, we investigated the antirotavirus activity using the bacterial supernatant, lysate, and the EPS obtained from $L$. plantarum LRCC5310 isolated from the Korean traditional fermented food kimchi in vitro and in vivo.

\section{MATERIALS AND METHODS}

\section{Screening, Isolation, and Identification of Lactobacillus plantarum LRCC5310}

Thirty-five kimchi samples were obtained from various local markets in Jecheon, Chungcheongbuk-do, Republic of Korea. The samples were cut into pieces and blended with $10 \mathrm{~mL}$ of peptone water $(0.85 \%$ mass/vol) in a tube. After serial dilution, the samples were spread on de Man, Rogosa, and Sharpe (MRS; Difco, Detroit, MI) agar plates and incubated at $37^{\circ} \mathrm{C}$ for 2 to $3 \mathrm{~d}$ in an aerobic incubator (Sanyo, Osaka, Japan). Representative single colonies were streaked several times to obtain pure cultures on MRS plates. The LAB isolates were identified by $16 \mathrm{~S}$ rRNA gene sequence analysis. Amplification of the 16S rRNA was conducted by PCR as per established procedures (Lane, 1991). The 16S rRNA amplicon was sequenced using a 3730 automatic DNA sequencer (Applied Biosystems, Foster City, CA) and the obtained sequences were analyzed using the NCBI BLAST program (https://blast.ncbi.nlm.nih .gov/Blast.cgi). The biochemical characteristics were determined using the API 50 CHL kit according to the manufacturer's instructions (bioMérieux, Marcy-
l'Étoile, France; https://apiweb.biomerieux.com). Finally, $263 \mathrm{LAB}$ were identified, and 1 of the identified LAB, L. plantarum LRCC5310, was selected for the evaluation of antirotaviral activity.

\section{Preparation of Supernatants, Lysates, and EPS}

Lactobacillus plantarum LRCC5310 cells were cultured in the MRS broth at $37^{\circ} \mathrm{C}$ for $2 \mathrm{~d}$. The supernatant was prepared after centrifugation at $10,000 \times g$ for 20 min at $4^{\circ} \mathrm{C}$ and the bacterial lysates were obtained by dissolving bacterial colonies in $1 \mathrm{~mL}$ of sterile distilled water using a sonicator for $10 \mathrm{~s}$. To prepare EPS, $L$. plantarum LRCC5310 cells were cultured in the MRS supplemented with $5 \%$ sucrose for $48 \mathrm{~h}$ at $37^{\circ} \mathrm{C}$; afterward, the samples were centrifuged at $10,000 \times g$ for $20 \mathrm{~min}$ at $4^{\circ} \mathrm{C}$. Supernatants were separated and slowly mixed with 2 volumes of cold $95 \%$ ethanol. Following a 30-min incubation at $4^{\circ} \mathrm{C}$, the polysaccharides were separated by centrifugation at $10,000 \times g$ for 20 min at $4^{\circ} \mathrm{C}$. The precipitated EPS samples were dried by using the vacuum at $4^{\circ} \mathrm{C}$. The purified EPS samples were identified using field-emission scanning electron microscopy (SEM 515; Philips, Eindhoven, the Netherlands).

\section{Antirotavirus Activity In Vitro}

Human rotavirus (HRV) Wa strain and MA104 cells obtained from the Korean Cell Line Bank (Seoul, Korea) were used for the infection and cultivation of rotavirus. The MA104 cells were grown in the $\alpha$-modified minimum essential medium ( $\alpha$-MEM; Gibco BRL, Grand Island, NY) containing 5\% fetal bovine serum (FBS; Gibco BRL) at $37^{\circ} \mathrm{C}$ in present of $5 \% \mathrm{CO}_{2}$. The HRV Wa strain $(0.2 \mathrm{~mL})$ at 0.01 multiplicity of infection was treated with the obtained supernatant, lysate, and EPS samples or the $\alpha$-MEM together with $10 \mu \mathrm{g} /$ $\mathrm{mL}$ of trypsin at $37^{\circ} \mathrm{C}$ for $1 \mathrm{~h}$ in a monolayer of MA104 cells. The MA104 cells were washed twice with PBS and infected using the prepared solutions at $37^{\circ} \mathrm{C}$ for 1 $\mathrm{h}$. We also included negative control samples containing nontreated cells. The unbound viruses were removed by 2 washes using fresh $\alpha$-MEM and $\alpha$-MEM supplemented with $5 \mu \mathrm{g} / \mathrm{mL}$ of trypsin. The samples were incubated at $37^{\circ} \mathrm{C}$ for $24 \mathrm{~h}$ in a $\mathrm{CO}_{2}$ incubator (Thermo Fisher, Waltham, MA). Antiviral activity was assessed by observing the cytopathic effect of the viruses using inverted light microscopy (DM IL; Leica, Wetzlar, Germany). Finally, viruses were harvested by 3 cycles of freezing and thawing, the samples were centrifuged at $1,000 \times g$ for $5 \mathrm{~min}$ at room temperature, and the supernatants were stored at $-80^{\circ} \mathrm{C}$ until further analyses. The presence of rotaviruses in MA104 cells was determined using quantitative real-time PCR (qPCR). 


\section{Rotavirus Quantification Using qPCR}

The rotavirus VP6 gene sequences of HRV Wa (VP6Wa-F, VP6-Wa-R, and VP6-Wa-Probe) and epidemic diarrhea of infant mice (EDIM-816F, EDIM-1031R, and EDIM-Probe) strains were used as the templates for real-time reverse transcription PCR. Viral RNA was extracted using a QIAamp Viral RNA Mini Kit (Qiagen, Valencia, CA), according to the manufacturer's instructions and stored at $-80^{\circ} \mathrm{C}$ until qPCR analysis. Reverse transcription PCR was performed for obtaining cDNA. The reaction mixture, containing 1 $\mathrm{U}$ of reverse transcriptase buffer, $0.2 \mathrm{p} M$ of each VP6 primer, $400 \mu M$ of deoxynucleotide triphosphates, and $1 \times$ reverse transcriptase buffer, was added to $5 \mu \mathrm{L}$ of viral RNA. Complementary DNA $(2 \mu \mathrm{L})$ was used for qPCR together with $5 \mu \mathrm{L}$ of the master mix (Applied Biosystems), $0.2 \mu \mathrm{L}$ each of the forward and reverse primers $(10 \mu M), 1.5 \mu \mathrm{L}$ of probe $(2 \mathrm{p} M$; Table 1$)$, and RNase-free water to reach a final volume of $10 \mu \mathrm{L}$. Using the ABI 7500 real-time thermocycler (Applied Biosystems), reverse transcription was performed for 2 min at $50^{\circ} \mathrm{C}$, followed by polymerase activation for 10 min at $95^{\circ} \mathrm{C}$. Forty cycles of denaturation for $15 \mathrm{~s}$ at $94^{\circ} \mathrm{C}$ and extension for $1 \mathrm{~min}$ at $60^{\circ} \mathrm{C}$ were performed. We finally obtained cycle threshold $(\mathrm{Ct})$ values and performed at least 3 independent experiments. Relative expression of the target gene was determined using the standard curve:

$$
\begin{aligned}
\text { Wa strain: } \mathrm{X} & =(35.631-\mathrm{Y}) / 4.4877, \text { and } \\
\text { EDIM: } \mathrm{X} & =(8.2797-\mathrm{Y}) / 0.2424 .
\end{aligned}
$$

\section{Antirotavirus Activity In Vivo}

Rotavirus EDIM (RV-EDIM) strain was used for the analysis of antirotavirus activity in BALB/c mouse model. The EDIM virus was titrated to $4 \times 10^{7}$ tissue culture infective dose $50 \% / \mathrm{mL}$ in MA104 cells and to 2 $\times 10^{4}$ focus-forming units (FFU) infective dose 50\%/ $\mathrm{mL}$ in mice using diarrhea as an endpoint, calculated by using the Reed-Muench formula (Reed and Muench, 1938). Animal studies were conducted in accordance with the Korean Food and Drug Administration (KFDA, 2011) guidelines. Samples were collected from mice in accordance with the animal ethical guidelines of the Chung-Ang University Institutional Animal Care and Use Committee of the Laboratory Animal Research Center (IACUC No. 2017-00044). Mice were housed in a cage under a 12-h light/dark cycle. The temperature and humidity were maintained at $24 \pm$ $2^{\circ} \mathrm{C}$ and $55 \pm 10 \%$, respectively. Pregnant BALB/c mice were purchased from Samtako Inc. (Osan, Korea). Four-day-old pups (each weighing approximately $2-4 \mathrm{~g}$ ) were used in the study. The mice were randomized into the experimental, negative (PBS) and positive (EDIMinfection) control groups ( $\mathrm{n}=8$ each). The pups were orally infected with the challenge dose $(10 \mu \mathrm{L}$ of $2 \times$ $10^{4} \mathrm{FFU}$ as infective dose $50 \% / \mathrm{mL}$ ) of the virus mixed with $10 \mu \mathrm{L}(1 \mathrm{mg} / \mathrm{mice})$ of EPS (EPS-treated EDIM virus) for 5 consecutive days (Ward et al., 1990; Tam and Roner, 2011; Kang et al., 2015). The mixtures were incubated at $24^{\circ} \mathrm{C}$ for $1 \mathrm{~h}$ in sterile screw-capped vials. Nontreated virus-infected control mice were infected with the combination of $2 \times 10^{4}$ FFU of viral suspension in $10 \mu \mathrm{L}$ of solution and $10 \mu \mathrm{L}$ of PBS, whereas the negative control mice received $20 \mu \mathrm{L}$ of PBS (PBS control). Stool consistency was evaluated using a fivepoint scale, where $0=$ normal, solid, and black; $1=$ soft brown; 2 = liquid brown; $3=$ soft yellow; and $4=$ liquid yellow (Shaw et al., 1995). Different stool consistencies reflect the amount of water lost during rotavirus infection. For this study, mice demonstrating level 3 or 4 stools were considered positive for diarrhea. Severity of diarrhea is reported as the diarrhea score ranging from 3 to 4 , where level 3 represents less severe and level 4 the most severe case. Stool samples were collected daily, and RV-EDIM shedding was confirmed using real-time PCR with the primers listed in Table 1. After $8 \mathrm{~d}$, these animals were anesthetized to obtain blood samples from their hearts, and were then euthanized by cervical dislocation; their small intestines were removed for histopathological analysis.

Table 1. Oligonucleotide primers and probes used in this study

\begin{tabular}{llll}
\hline Gene & Primer & Sense & Sequence $\left(5^{\prime} \text { to } 3^{\prime}\right)^{1}$ \\
\hline VP6-Wa & VP6-Wa-F & + & AATGGAGTAGCGCCACAATC \\
& VP6-Wa-R & - & TAAGCCACATGGTTCCCATT \\
VP6-EDIM & VP6-Wa-Probe & + & 6FAM-GCACCGGATTTGTTTTCAT-MGBNFQ \\
& EDIM-816F & + & TTGAACGGTCAGGTCATCAA \\
& EDIM-1031R & - & CGCGAGAACTGATTCACAAA \\
& EDIM-Probe & + & 6FAM-AATTGATGAGACCGCCAAAC-MGBNFQ \\
\hline
\end{tabular}

${ }^{1} 6 \mathrm{FAM}=6$-carboxyfluorescein; MGBNFQ $=$ minor groove binder nonfluorescent quencher. 


\section{Cytokine Level Determination In Vitro and In Vivo}

To determine the immune modulatory effect of $L$. plantarum LRCC5310, cytokine concentrations in the human colon adenocarcinoma cell line Caco-2, murine macrophage-like RAW264.7 cells, and mouse blood were examined using an ELISA kit (R\&D systems, Minneapolis, MN) according to the manufacturer's instructions (https://www.rndsystems.com/products/ elisas). Levels of the cytokines IL-6, IL-10, IL-13, tumor necrosis factor (TNF)- $\alpha$, and IFN- $\gamma$ were determined in the LPS-stimulated RAW 264.7 cells and Caco-2 cells; TNF- $\alpha$ levels were determined in mouse serum samples as well. The RAW264.7 cells were cultured in Dulbecco's modified Eagle's medium (Gibco BRL) supplemented with $10 \%$ FBS and then seeded at the density of $2 \times 10^{5}$ cells/well in 24-well plates and incubated at $37^{\circ} \mathrm{C}$ in the presence of $5 \% \mathrm{CO}_{2}$. Caco-2 cells were cultured in the minimum essential medium (Gibco BRL) supplemented with 10\% FBS containing $100 \mathrm{U} / \mathrm{mL}$ of penicillin at $37^{\circ} \mathrm{C}$ in the presence of $5 \%$ $\mathrm{CO}_{2}$. To achieve cell adherence, cells were incubated for $24 \mathrm{~h}$ and stimulated with $0.1 \mu \mathrm{g} / \mathrm{mL}$ of LPS. The LPS-stimulated RAW 264.7 cells were treated with 100 $\mu \mathrm{g} / \mathrm{mL}$ of L. plantarum LRCC5310 EPS and incubated for $24 \mathrm{~h}$. The blood was kept at $37^{\circ} \mathrm{C}$ for $1 \mathrm{~h}$ and centrifuged at $1,500 \times g$ for $10 \mathrm{~min}$ at $4^{\circ} \mathrm{C}$ to obtain the neonatal mouse serum samples.

\section{Histopathological Analysis}

Small intestine sections were excised and perfused with formalin. The sections were kept immersed in formalin for $1 \mathrm{~d}$, after which they were transferred to $70 \%$

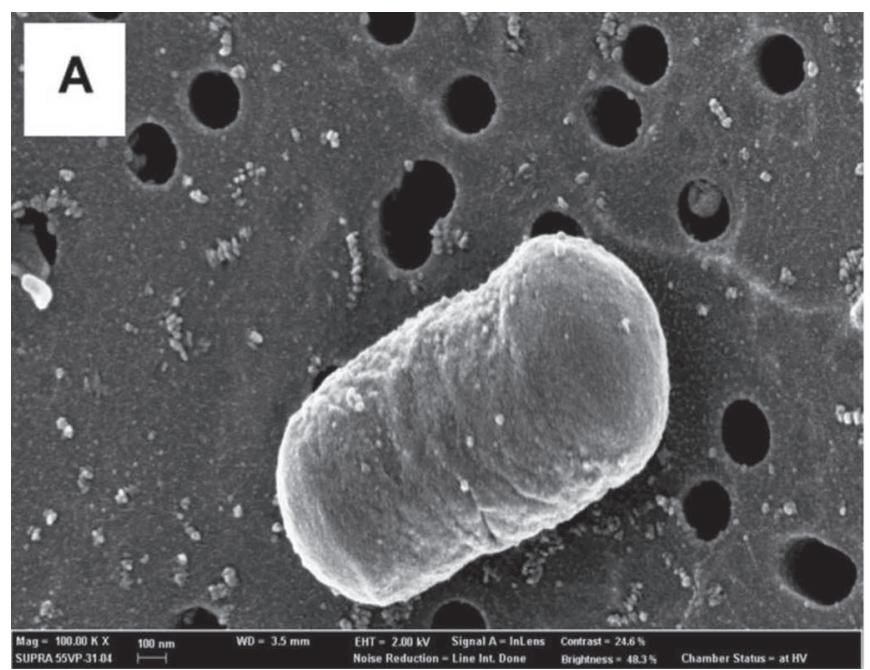

ethanol. The samples were embedded in paraffin and the sections were stained with hematoxylin and eosin using standard protocols. We performed a blind analysis of samples to identify rotavirus infection-associated pathological changes (Boshuizen et al., 2003).

\section{Statistical Analysis}

The results were expressed as mean \pm standard error of the means of 3 technical replicates. All experiments were performed twice independently. Comparison between the control and different treatment groups was performed by using one-way ANOVA with Dunnett's post-test or by Mann-Whitney U test as indicated, using GraphPad Prism (version 6.0; GraphPad Software, San Diego, CA). $P$-values of $<0.05$ were considered statistically significant.

\section{RESULTS}

\section{EPS from Extraction from L. plantarum LRCC5310}

We examined the cellular shape and EPS of $L$. plantarum LRCC5310 strain using scanning electron microscopy and observed rod-shaped cells with EPS components on the cell surface (Figure 1A). The EPS was observed as smooth bulges attached to the bacterial cell surface (Figure 1B), resulting in morphological changes. The EPS extraction yielded $636 \pm 9.67 \mathrm{mg} / \mathrm{L}$ $(\mathrm{wt} / \mathrm{vol})$ of the substance from $3.4-4.11 \times 10^{8} \mathrm{cfu} / \mathrm{mL}$ of cultured L. plantarum LRCC5310 in MRS medium with $5 \%$ sucrose. We dissolved the extracted EPS pellets in double-distilled water.

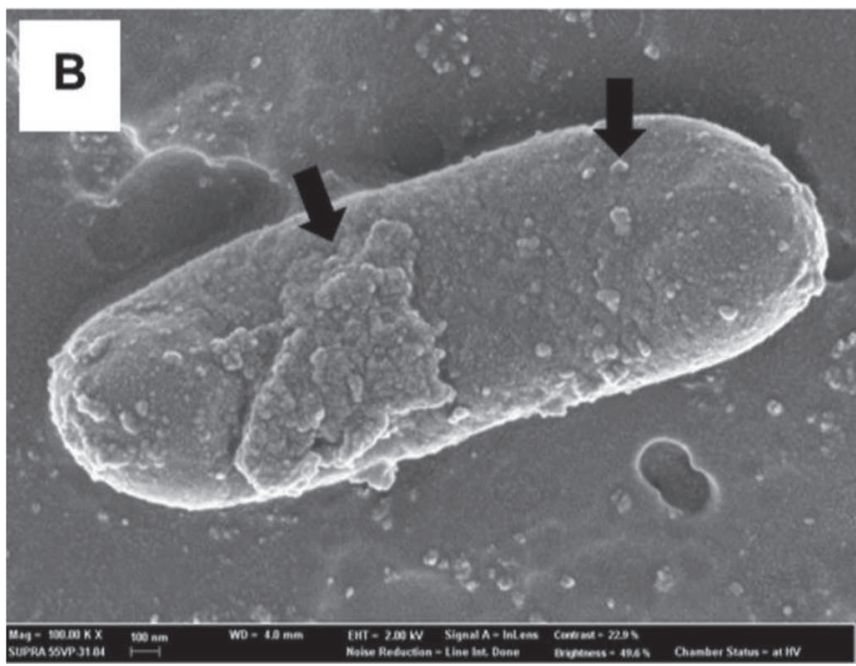

Figure 1. Cellular shape and exopolysaccharides (EPS) production. (A) Cellular shape of Lactobacillus plantarum LRCC5310 strain; (B) EPS observed on the surface of L. plantarum LRCC5310, where the arrows indicate EPS on the bacterial cell surface. 

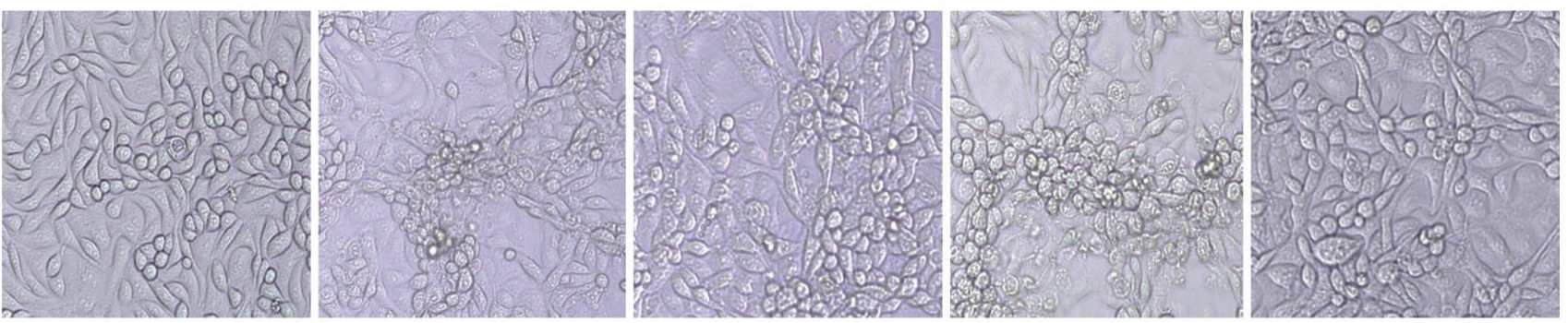

(B)

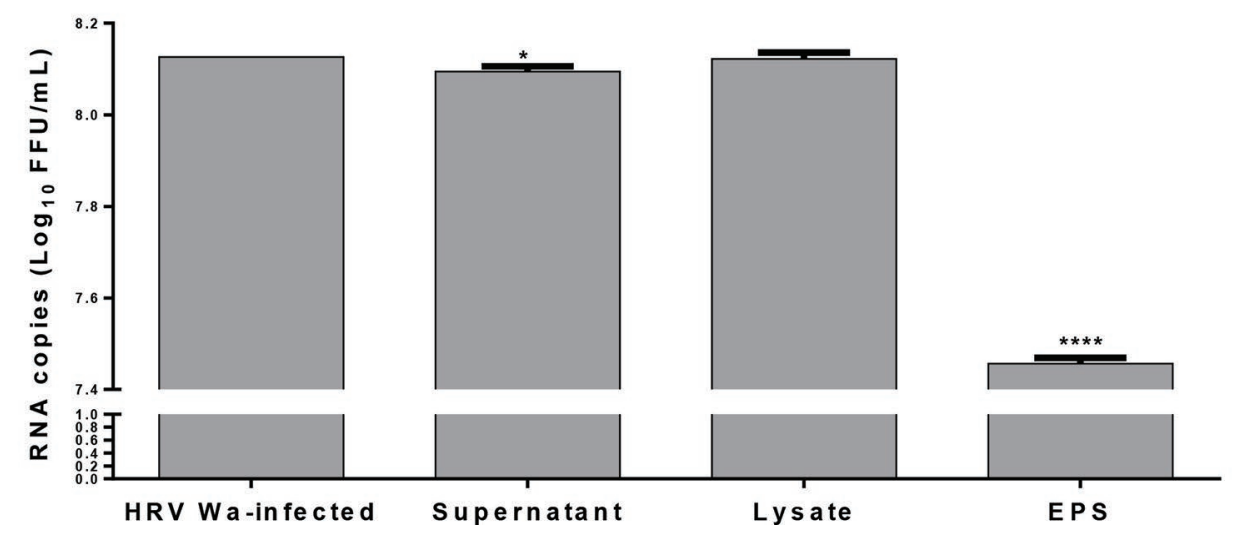

Figure 2. Effect of Lactobacillus plantarum LRCC5310-produced supernatants, lysates, and exopolysaccharides (EPS) on viral replication. (A) Cytopathic effects observed following the treatment of rotavirus-infected MA104 cells with supernatant, lysate, and EPS. (B) Quantitative real-time PCR analysis of the antiviral effects of L. plantarum strain-obtained supernatant and EPS. The PCR data are expressed as mean \pm SEM; ${ }^{*} P<0.05,{ }^{* * * *} P<0.0001$. FFU $=$ focus forming units. Color version available online.

\section{Effects of L. plantarum LRCC5310 EPS on Rotavirus Replication In Vitro}

We used light microscopy to observe the morphological changes in MA104 cells (Figure 2A), observing cytopathic effects such as cell detachment, obscure borders, rounding, and fusion in HRV Wa-infected cultures. Furthermore, we determined that the supernatant treatment had weak inhibitory effects on the infection, whereas the EPS treatment strongly suppressed HRVWa infection in MA104 cells compared with that in the HRV Wa-infected group. No inhibitory effects were observed in the lysate-treated MA104 cultures. To confirm these results, we examined the supernatants, lysates, and EPS samples of the L. plantarum LRCC5310 strain by using real-time PCR (Figure 2B). The supernatant $(50 \mu \mathrm{L} / \mathrm{mL})$ showed weak antiviral activity $(P<0.001)$, reducing the viral RNA copy numbers to 8.09 log compared with those in the HRV Wa-infected samples $(8.13 \log )$. However, the EPS at $1.95 \mathrm{mg} / \mathrm{mL}$ showed strong antiviral activity $(P<0.001)$, reducing the viral RNA copy numbers to 7.46 log compared with those determined in the HRV Wa-infected group. The lysate samples $(8.12 \mathrm{log})$ did not show any antiviral activity.

\section{L. plantarum LRCC5310 EPS Effects on the Infected Neonatal Mice}

We administrated $1 \mathrm{mg}$ of EPS to each mouse infected with the rotavirus for 7 consecutive days. To explore the antirotavirus activity of EPS in vivo, newborn mice were pretreated with EPS for $2 \mathrm{~d}$, followed by the inoculation of RV-EDIM together with EPS (1 mg/ mouse) for $5 \mathrm{~d}$. At 20,000 FFU/mouse, the number of newborn mice that developed RV-EDIM-induced diarrhea in the EPS-treated group was significantly lower $(50 \% ; P<0.01)$ after $d 7$ than that in the EDIM virus only-infected group (100\%; Figure 3A). Furthermore, we showed that administration of EPS (1 mg/mouse for 5 d) to 8 mice (4-d-old) with acute diarrhea and severe dehydration resulted in significantly decreased $(P<$ 
(A)

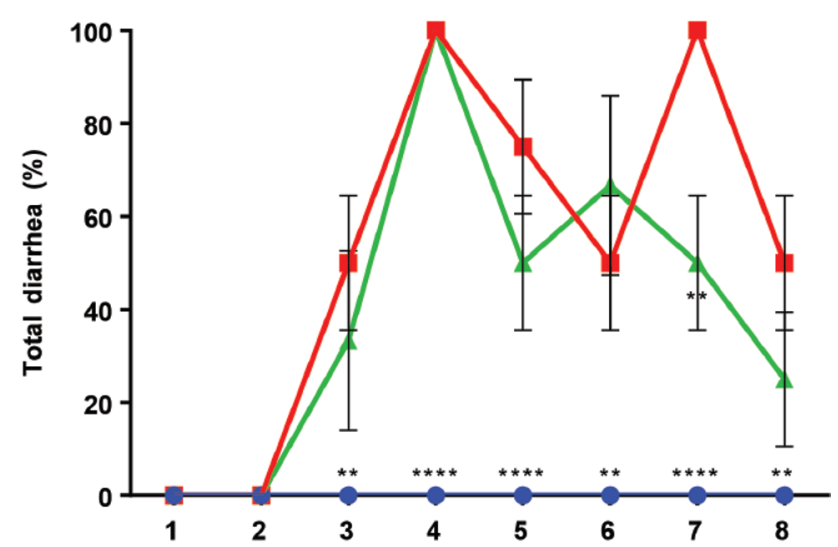

(B)

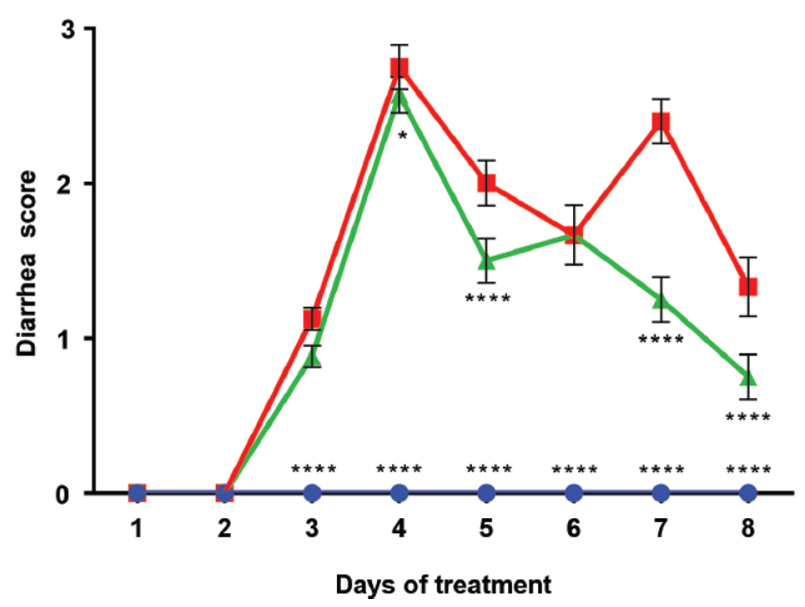

Figure 3. Effects of exopolysaccharides (EPS) treatment in vivo. (A) The percentage of infected mice and (B) diarrhea score alterations in neonatal mice inoculated with rotavirus and treated or not with EPS. The percentage of infected mice was calculated using the number of diarrheic mice and the number of total samples collected each day. The mean diarrheal score was determined by shape and color of stool samples collected each day. Percentage and score data are expressed as mean $\pm \mathrm{SEM} ;{ }^{*} P<0.05 ;{ }^{* *} P<0.01 ;{ }^{* * * *} P<0.0001$, compared with the epidemic diarrhea of infant mice (EDIM)-infected group. $\bullet=$ PBS group; = EDIM-infected group; $\boldsymbol{\Lambda}=$ EPS-treated group. Color version available online.

0.01 ) mean diarrhea score after $\mathrm{d} 7$ and 8 , to 1.25 and 0.75 , respectively, in the EPS-treated group, and 2.4 and 1.33, respectively, in the EDIM virus only-infected group (Figure 3B).

\section{Viral Shedding}

To confirm the effects of the EPS on the viral load, we isolated total cellular RNA from the feces of pups treated with L. plantarum LRCC5310 EPS and analyzed it using real-time PCR to determine copy numbers of the RV-EDIM VP6 gene. The highest fecal RV-EDIM RNA shedding titer was obtained at d 4 to 7 following the infection. No significant differences in shedding titer were observed between the EPS-treated and EDIM virus only-infected groups from d 1 to 4 . However, the titer values obtained on $\mathrm{d} 8$ were $2.86 \log (0.73 \pm 0.002$ $\left.\times 10^{3} \mathrm{FFU} / \mathrm{mL} ; P<0.0001\right)$ for the EPS-treated group and $4.30 \log \left(20 \pm 0.15 \times 10^{3} \mathrm{FFU} / \mathrm{mL}\right)$ for the EDIM virus only-infected group (Figure 4 ). We did not detect any viruses in the PBS-treated group.

(A)

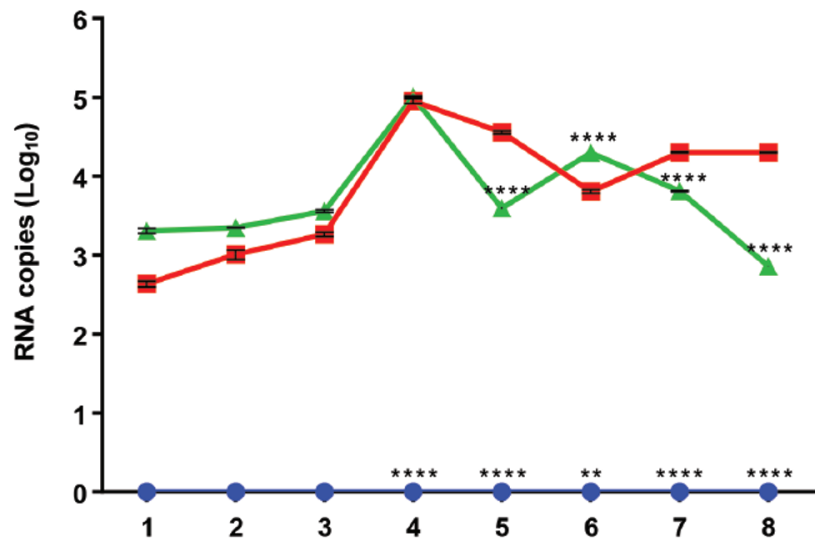

(B)

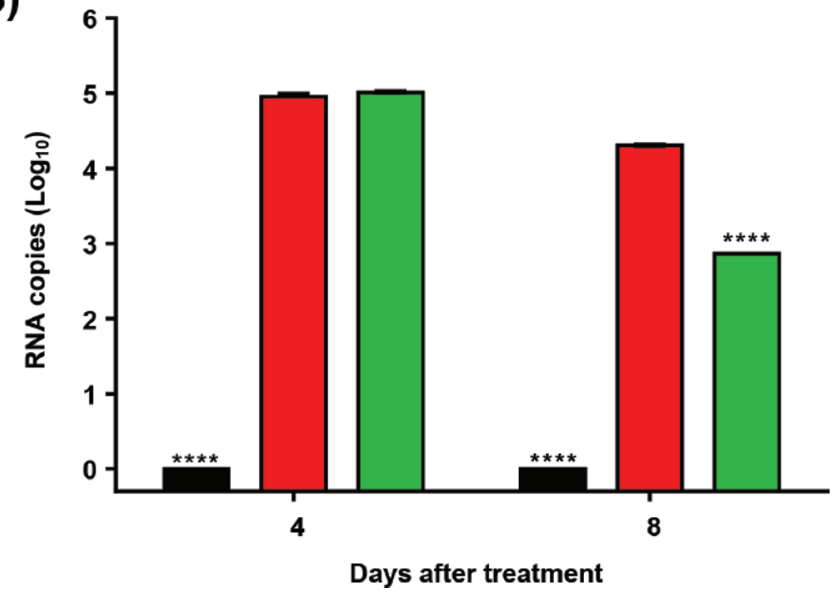

Figure 4. Effects of the exopolysaccharides (EPS) on viral shedding. The antirotaviral activity of EPS is expressed as the viral RNA copies compared with epidemic diarrhea of infant mice (EDIM)infected group; the experiments were carried out for $8 \mathrm{~d}$. (A) Viral shedding determined using the stool samples of the neonatal mice inoculated with PBS, rotavirus only, and EPS. (B) Quantification of the obtained results at $\mathrm{d} 4$ and 8 . Data are represented as mean values \pm SEM; $* * P<0.01 ; * * * * P<0.0001$, compared with the rotavirusinfected group. (black) $=$ PBS group; $($ dark gray $)=$ EDIMinfected group; $\boldsymbol{\Delta}$ (light gray) = EPS-treated group. Color version available online. 
(A)

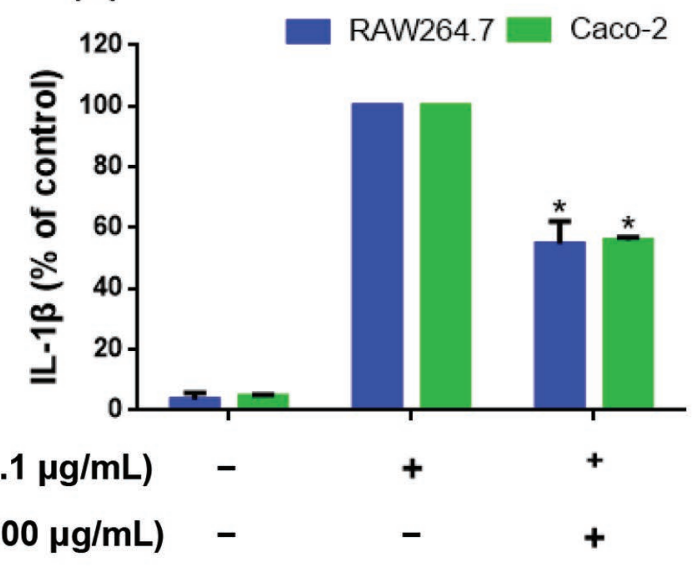

(C)

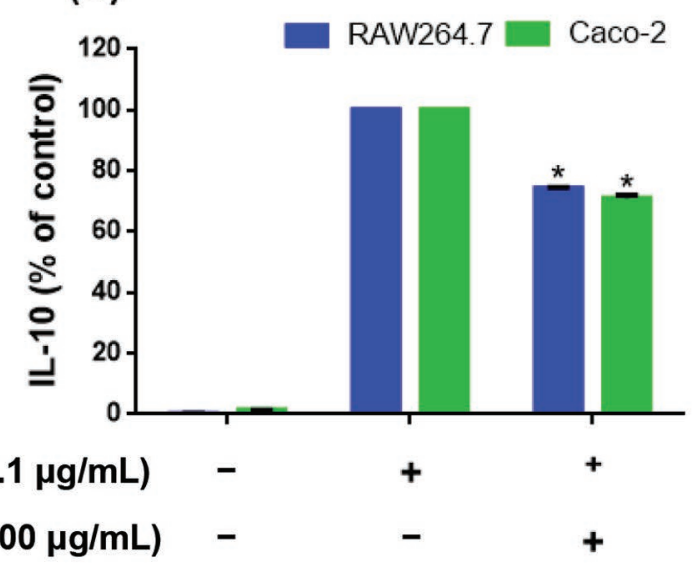

(B)

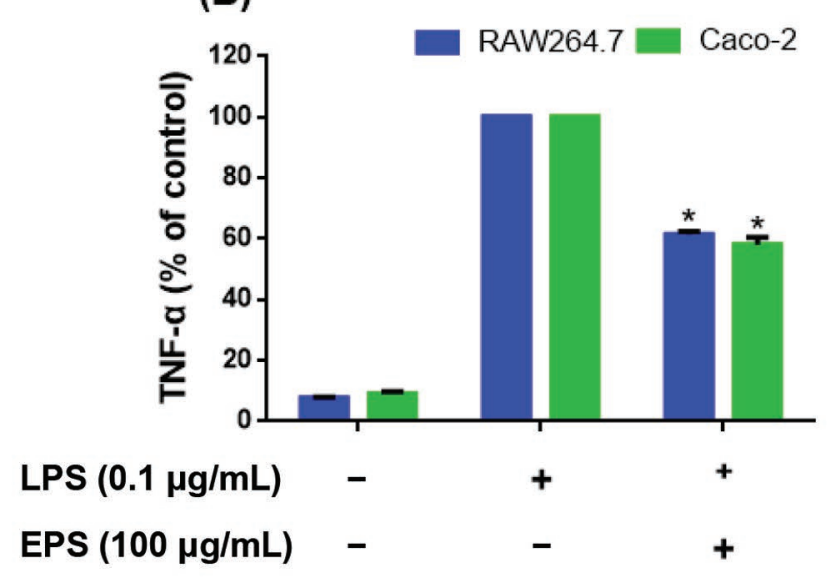

(D)

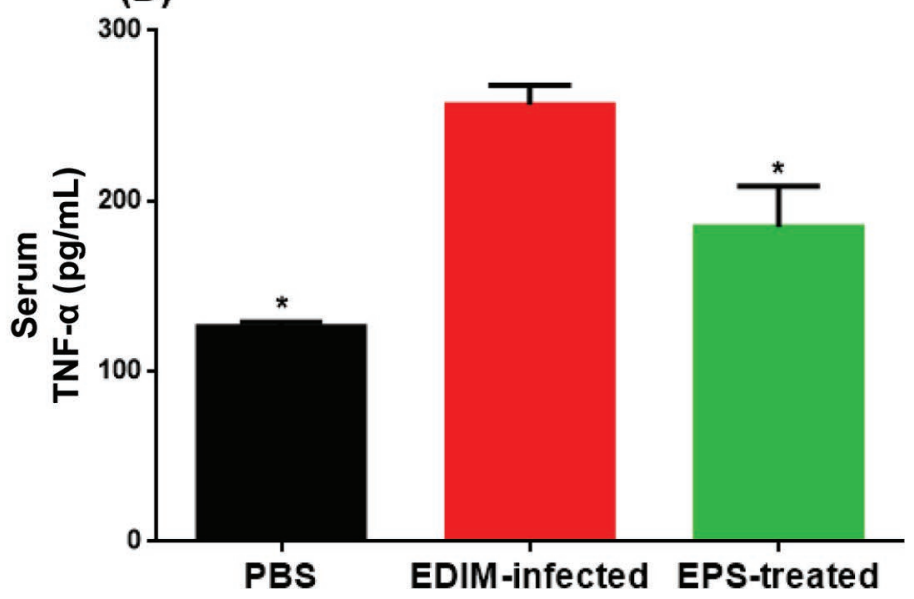

Figure 5. Cytokine levels following the rotavirus infection and exopolysaccharide (EPS) treatment in vitro and in vivo. (A) Interleukin-1 $\beta$, (B) tumor necrosis factor (TNF)- $\alpha$, and (C) IL-10 levels in the LPS-treated, EPS-treated, and untreated RAW 264.7 cells and Caco-2 cells. Data are expressed as mean values \pm SEM, compared with the LPS-treated group. (D) The TNF- $\alpha$ level in rotavirus only-treated (EDIM $=$ epidemic diarrhea of infant mice) and EPS-treated mouse serum samples. Data are expressed as mean values \pm SEM; ${ }^{*} P<0.01$, compared with the rotavirus-infected group. Color version available online.

\section{Inflammatory Response After Viral Infection}

To confirm cytokine secretion in the LPS-stimulated RAW264.7 cells and Caco-2 cells, we performed ELISA to quantify the cytokine concentration (Figure $5 \mathrm{~A}-5 \mathrm{C}$ ). Proinflammatory cytokine levels, including those of IL-1 $\beta$ and TNF- $\alpha$, and the level of IL-10, an antiinflammatory cytokine, decreased in the EPS-treated cells $(P<0.01)$ compared with those in the LPStreated RAW 264.7 cells and Caco-2 cells. However, we observed that IL- 6 and IFN- $\gamma$ levels did not change between the groups. We further examined the levels of TNF- $\alpha$, due to its associations with the viral infection and inflammation in the intestine, in vivo using mouse serum samples and showed that its levels significantly decreased following the EPS treatment $(184.5 \mathrm{pg} / \mathrm{mL}$;
$P<0.01)$ compared with those in the EDIM-infected cells $(256.6 \mathrm{pg} / \mathrm{mL}$; Figure 5D).

\section{Pathological Changes in the Small Intestine}

We performed an intragastric staining of intestines using hematoxylin and eosin stains to determine the pathological changes in the rotavirus-infected mice. We observed considerable changes, including vacuolar degeneration, edema and intestinal wall congestion, and the destruction of enteric epithelium integrity compared with those in the PBS-treated control group (Figure 6). However, in the EPS-treated group, the border of villi was clear, although some intestinal wall edema was observed. Compared with the PBS-treated 

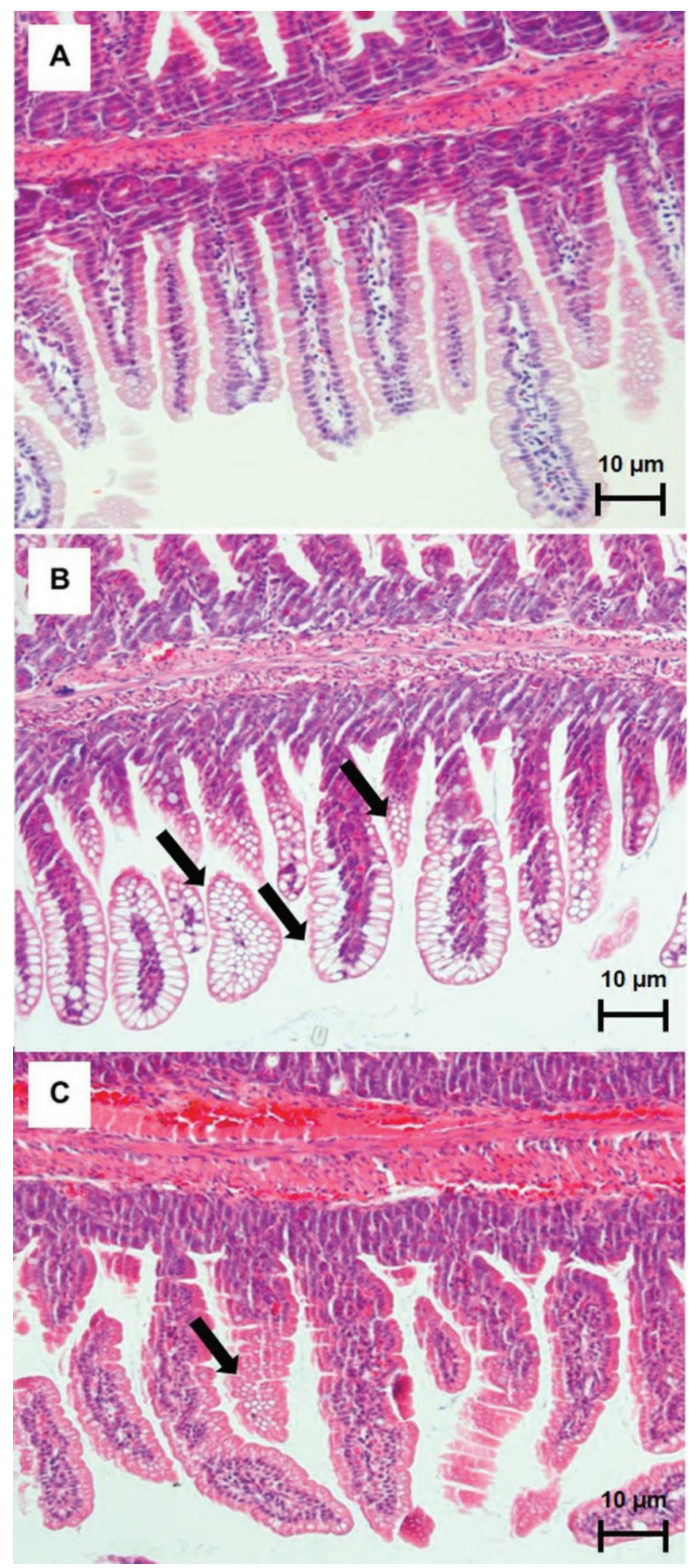

Figure 6. Hematoxylin and eosin staining of the infected and exopolysaccharides (EPS)-treated mouse intestines; (A) PBS-treated group, (B) rotavirus only-treated group. Typical vacuolation can be observed in the (C) EPS-treated group. The arrows indicate vacuoles and destruction of the barrier in the intestine. Color version available online. control group, the EPS-treated group showed smaller and fewer vacuoles in villi.

\section{DISCUSSION}

The World Health Organization recommends use of rotavirus vaccine, but the cost of the 2 currently available rotavirus vaccines is relatively high (Muhsen et al., 2010; Esposito et al., 2011). However, few specific treatments for rotavirus diarrhea exist to date, oral rehydration, breast feeding, and early refeeding among the treatments recommended (Chow et al., 2010). Lactobacillus was shown to reduce the risk for development of diarrhea and rotavirus infection (Shornikova et al., 1997a), and Lactobacillus rhamnosus GG, a representative probiotic strain, was shown to have a positive effect on the rotavirus-induced gastroenteritis in hospitalized infants and children (Sindhu et al., 2014). Recently, many studies focused on $L$. plantarum, demonstrating its antiviral effects against influenza virus and cutaneous herpes simplex virus by inducing a stronger immune response (Yang et al., 2017). Moreover, L. plantarum has been known to reinforce the intestinal barrier and to reduce intestinal permeability in animal studies (Mujagic et al., 2017). Despite the indications that $L$. plantarum has beneficial antiviral effects, the activity of this bacterium against rotavirus has not been elucidated completely.

Recently, EPS produced by LAB have attracted research attention as a natural biopolymer for the nutrition science applications. Exopolysaccharides are carbohydrate polymers that form extracellular layers on the surface of different bacterial strains (Dertli et al., 2016), and those produced by LAB were shown to have antitumor, immune system-activating, and serum cholesterol-lowering effects; they may also function as prebiotics (Patel et al., 2014). Exopolysaccharides additionally induce T-lymphocyte activation (Ruas-Madiedo et al., 2002), macrophage activation, and cytokine activity (Kitazawa et al., 1996).

Generally, anti-rotaviral activity can be examined using plaque and qPCR assays (Gautam et al., 2015); however, plaque assay has limited usefulness in the quantification of the virus levels (Edelman and Barletta, 2003), whereas qPCR is a sensitive method routinely used to determine the viral load in human and animal feces. Indeed, previous studies showed significant correlations between rotaviral load determined by PCR analysis in stool and disease severity in children with acute gastroenteritis (Günaydın et al., 2016), analyzing the viral VPry gene (Gautam et al., 2016). However, the highest serum titers of human antibodies binding to rotaviruses postinfection are typically directed against $V P 6$, which is highly immunogenic and contains con- 
served epitopes in rotavirus groups A and C (Kumar et al., 2016).

We performed qPCR assay by targeting the VP6 gene, which showed that the applied treatment led to the suppression of rotavirus infection. We investigated the antiviral effects of the L. plantarum LRCC5310produced EPS against rotavirus using a rotavirusinfected neonatal mouse model. Exopolysaccharide, orally administrated to mice, reduced the duration of acute rotavirus-induced diarrhea and significantly reduced rotavirus shedding in mice in comparison with those in the control group at d 8 postinfection. These results are in agreement with those reported in a previous study, which showed that $L$. reuteri SD2112 has a positive effect on the rotavirus-associated diarrhea in clinical trials (Shornikova et al., 1997b). Furthermore, the L. plantarum EPS reduced the extent of damage to the intestinal epithelium after rotavirus infection compared with that in the controls. These results suggest that EPS treatment may offer some protective effects during rotavirus infection.

Murine macrophage-like RAW 264.7 cells are frequently used to determine the cytokine response to virus, bacteria, and natural substances in immune studies (Yamamoto et al., 2007; Kim et al., 2011; Pott et al., 2011). Furthermore, rotavirus induces the activating cytokine inflammation response in intestinal epithelial cells (Rollo et al., 1999). In our study, the cytokine response was determined in the RAW 264.7 and Caco-2 cell lines, and the 2 cell lines showed similar cytokine response patterns in vitro; the levels of IL-1 $\beta$, TNF- $\alpha$, and IL-10 were decreased in the EPS-treated group compared with the LPS-treated group. Moreover, EPS effects, preventing rotavirus infection of cells and mice, were demonstrated by using a cytokine assay (Bleau et al., 2010). A probiotic may decrease the production of TNF- $\alpha$ directly or indirectly by suppressing a variety of proinflammatory cytokines, such as IL-6 and IL-8 (Weninger and von Andrian, 2003). Our in vitro analyses showed increased levels of anti-inflammatory cytokine, IL-10, together with the decrease in the levels of proinflammatory cytokines, IL- $1 \beta$ and TNF- $\alpha$, following the treatment of cells with $L$. plantarum LRCC5310 EPS. In particular, TNF- $\alpha$, which plays an important role in immune modulation for maintenance of intestinal homeostasis, is associated with severe diarrhea and the inflammatory state during rotaviral infection in children (Jiang et al., 2003; Zhang et al., 2016). The level of TNF- $\alpha$ in blood sera was determined after in vivo administration of EPS $2 \mathrm{~d}$ before the rotavirus infection, and the results indicated the suppression of TNF- $\alpha$ activity, which is in agreement with previously published results (Zhang et al., 2005). Taken together, our results demonstrate that the $L$. plantarum EPS may help preserve the intestinal mucosa against rotavirus by suppressing the secretion and activity of TNF- $\alpha$; likewise, our results suggest that the mechanisms underlying this process include the regulation of the inflammatory responses.

We observed cellular vacuolation and degeneration in the intestines of EDIM-infected mice, consistent with previous studies (Guerin-Danan et al., 1998). Lactobacillus can alleviate the diarrhea and inhibit the replication of rotavirus by improving intestinal barrier function (Mao et al., 2016). Our results suggest that $L$. plantarum LRCC5310 EPS could help protect the intestinal mucosal barrier from viral shedding and other damages caused by virus infection.

In summary, our study demonstrated that L. plantarum LRCC5310 EPS exhibits potent antirotavirus activity in vitro, especially against extracellular rotaviruses. Furthermore, the EPS displayed high rate of adhesion, thus interfering with the rotaviral attachment to MA104 cells in vitro. Lactobacillus plantarum LRCC5310 EPS in vivo reduced the duration of diarrhea, limited epithelial lesions, decreased rotavirus replication in the intestine, and shortened the time to recovery of suckling mice. Further investigations of the underlying mechanisms are required, which may lead to the development of $L$. plantarum LRCC5310 EPS as a potential antirotavirus therapeutic agent or oral adjuvant.

\section{ACKNOWLEDGMENTS}

This work was supported by the Lotte Foods Co. Ltd. (Seoul, Republic of Korea) in 2015.

\section{REFERENCES}

Barreto, F. M., A. N. C. Simão, H. K. Morimoto, M. A. B. Lozovoy, I. Dichi, and L. H. da Silva Miglioranza. 2014. Beneficial effects of Lactobacillus plantarum on glycemia and homocysteine levels in postmenopausal women with metabolic syndrome. Nutrition 30:939-942.

Bleau, C., A. Monges, K. Rashidan, J. P. Laverdure, M. Lacroix, M. R. Van Calsteren, M. Millette, R. Savard, and L. Lamontagne. 2010. Intermediate chains of exopolysaccharides from Lactobacillus rhamnosus $\mathrm{RW}-9595 \mathrm{M}$ increase IL-10 production by macrophages. J. Appl. Microbiol. 108:666-675.

Boshuizen, J. A., J. H. Reimerink, A. M. Korteland-van Male, V. J. van Ham, M. P. Koopmans, H. A. Büller, J. Dekker, and A. W. Einerhand. 2003. Changes in small intestinal homeostasis, morphology, and gene expression during rotavirus infection of infant mice. J. Virol. 77:13005-13016.

Brinques, G. B., and M. A. Z. Ayub. 2011. Effect of microencapsulation on survival of Lactobacillus plantarum in simulated gastrointestinal conditions, refrigeration, and yogurt. J. Food Eng. 103:123-128.

Caggianiello, G., M. Kleerebezem, and G. Spano. 2016. Exopolysaccharides produced by lactic acid bacteria: from health-promoting benefits to stress tolerance mechanisms. Appl. Microbiol. Biotechnol. 100:3877-3886. 
Chang, J. H., Y. Shim, S. K. Cha, and K. Chee. 2010. Probiotic characteristics of lactic acid bacteria isolated from kimchi. J. Appl. Microbiol. 109:220-230.

Chang, J. Y., and H. C. Chang. 2011. Growth inhibition of foodborne pathogens by kimchi prepared with bacteriocin-producing starter culture. J. Food Sci. 76:M72-M78.

Chow, C. M., A. K. Leung, and K. L. Hon. 2010. Acute gastroenteritis: from guidelines to real life. Clin. Exp. Gastroenterol. 3:97-112.

Ciszek-Lenda, M., B. Nowak, M. Śróttek, A. Gamian, and J. Marcinkiewicz. 2011. Immunoregulatory potential of exopolysaccharide from Lactobacillus rhamnosus KL37. Effects on the production of inflammatory mediators by mouse macrophages. Int. J. Exp. Pathol. 92:382-391.

Dertli, E., E. Mercan, M. Arıcı, M. T. Yılmaz, and O. Sağdıç. 2016. Characterisation of lactic acid bacteria from Turkish sourdough and determination of their exopolysaccharide (EPS) production characteristics. Lebensm. Wiss. Technol. 71:116-124.

Edelman, D. C., and J. Barletta. 2003. Real-time PCR provides improved detection and titer determination of bacteriophage. Biotechniques 35:368-375.

Esposito, D. H., J. E. Tate, G. Kang, and U. D. Parashar. 2011. Projected impact and cost-effectiveness of a rotavirus vaccination program in India, 2008. Clin. Infect. Dis. 52:171-177.

Gautam, R., S. Mijatovic-Rustempasic, M. D. Esona, K. I. Tam, O. Quaye, and M. D. Bowen. 2016. One-step multiplex real-time RTPCR assay for detecting and genotyping wild-type group A rotavirus strains and vaccine strains (Rotarix ${ }^{\circledR}$ and RotaTeq ${ }^{\circledR}$ ) in stool samples. PeerJ 4:e1560.

Gautam, R. S. Mijatovic-Rustempasic, S. Roy, M. D. Esona, B. Lopez, Y. Mencos, G. Rey-Benito, and M. D. Bowen. 2015. Full genomic characterization and phylogenetic analysis of a zoonotic human G8P [14] rotavirus strain detected in a sample from Guatemala. Infect. Genet. Evol. 33:206-211.

Guerin-Danan, C., J. Meslin, F. Lambre, A. Charpilienne, M. Serezat, C. Bouley, J. Cohen, and C. Andrieux. 1998. Development of a heterologous model in germfree suckling rats for studies of rotavirus diarrhea. J. Virol. 72:9298-9302.

Gugliandolo, C., A. Spanò, V. Lentini, A. Arena, and T. Maugeri. 2014. Antiviral and immunomodulatory effects of a novel bacterial exopolysaccharide of shallow marine vent origin. J. Appl. Microbiol. 116:1028-1034.

Günaydın, G., S. Yu, T. Gräslund, L. Hammarström, and H. Marcotte. 2016. Fusion of the mouse IgG1 Fc domain to the VHH fragment (ARP1) enhances protection in a mouse model of rotavirus. Sci Rep. 6:30171.

Hemming, M., and T. Vesikari. 2014. Detection of rotateq vaccine-derived, double-reassortant rotavirus in a 7-year-old child with acute gastroenteritis. Pediatr. Infect. Dis. J. 33:655-656.

Hidalgo-Cantabrana, C., P. López, M. Gueimonde, G. Clara, A. Suárez, A. Margolles, and P. Ruas-Madiedo. 2012. Immune modulation capability of exopolysaccharides synthesised by lactic acid bacteria and bifidobacteria. Probiotics Antimicrob. Proteins 4:227-237.

Inturri, R., A. Molinaro, F. Di Lorenzo, G. Blandino, B. Tomasello, C. Hidalgo-Cantabrana, C. De Castro, and P. Ruas-Madiedo. 2017. Chemical and biological properties of the novel exopolysaccharide produced by a probiotic strain of Bifidobacterium longum. Carbohydr. Polym. 174:1172-1180.

Ismail, B., and K. M. Nampoothiri. 2010. Production, purification and structural characterization of an exopolysaccharide produced by a probiotic Lactobacillus plantarum MTCC 9510. Arch. Microbiol. 192:1049-1057.

Jeong, S., I. Lim, and W. Kim. 2016. Differentiation of RotaTeq ${ }^{\circledR}$ vaccine strains from wild-type strains using NSP3 gene in reverse transcription polymerase chain reaction assay. J. Virol. Methods 237:72-78.

Jiang, B., L. Snipes-Magaldi, P. Dennehy, H. Keyserling, R. C. Holman, J. Bresee, and R. I. Glass. 2003. Cytokines as mediators for or effectors against rotavirus disease in children. Clin. Diagn. Lab. Immunol. 10:995-1001.

Kang, J. Y., D. K. Lee, N. J. Ha, and H. S. Shin. 2015. Antiviral effects of Lactobacillus ruminis SPM0211 and Bifidobacterium long- um SPM1205 and SPM1206 on rotavirus-infected Caco-2 cells and a neonatal mouse model. J. Microbiol. 53:796-803.

KFDA (Food and Drug Administration of Korea). 2011. Korean FDA Guidelines for Bioequivalence Test. KFDA, Seoul, Korea.

Khan, I., and S. C. Kang. 2016. Probiotic potential of nutritionally improved Lactobacillus plantarum DGK-17 isolated from Kimchi-A traditional Korean fermented food. Food Control 60:88-94.

Kim, B. K., J. M. Choi, S. A. Kang, K. Y. Park, and E. J. Cho. 2014a. Antioxidative effects of Kimchi under different fermentation stage on radical-induced oxidative stress. Nutr. Res. Pract. 8:638-643.

Kim, D., Y. Yamasaki, Z. Jiang, Y. Nakayama, T. Yamanishi, K. Yamaguchi, and T. Oda. 2011. Comparative study on modeccin-and phytohemagglutinin (PHA)-induced secretion of cytokines and nitric oxide (NO) in RAW264. 7 cells. Acta Biochim. Biophys. Sin. (Shanghai) 43:52-60.

Kim, H.-Y., J.-L. Song, H.-K. Chang, S.-A. Kang, and K.-Y. Park. 2014b. Kimchi protects against azoxymethane/dextran sulfate sodium-induced colorectal carcinogenesis in mice. J. Med. Food 17:833-841.

Kitazawa, H. T. Itoh, Y. Tomioka, M. Mizugaki, and T. Yamaguchi. 1996. Induction of IFN- $\gamma$ and IL-1 $\alpha$ production in macrophages stimulated with phosphopolysaccharide produced by Lactococcus lactis ssp. cremoris. Int. J. Food Microbiol. 31:99-106.

Kleerebezem, M., P. Hols, E. Bernard, T. Rolain, M. Zhou, R. J. Siezen, and P. A. Bron. 2010. The extracellular biology of the lactobacilli. FEMS Microbiol. Rev. 34:199-230.

Kumar, N., Y. S. Malik, S. Kumar, K. Sharma, S. Sircar, S. Saurabh, B. R. Gulati, N. Singh, A. K. Singh, and V. G. Joshi. 2016. Peptide-recombinant VP6 protein based enzyme immunoassay for the detection of group a rotaviruses in multiple host species. PLoS One 11:e0159027.

Kwak, S. H., Y.-M. Cho, G.-M. Noh, and A.-S. Om. 2014. Cancer preventive potential of Kimchi lactic acid bacteria (Weissella cibaria Lactobacillus plantarum). J. Cancer Prev. 19:253-258.

Lane, D. 1991. 16S/23S rRNA sequencing. Pages 115-175 in Nucleic Acid Techniques in Bacterial Systematics. E. Stackebrandt and M. Goodfellow, ed. John Wiley and Sons, Chichester, UK.

Lee, H., D. Y. Kim, M. A. Lee, J.-Y. Jang, and R. Choue. 2014. Immunomodulatory effects of Kimchi in Chinese healthy college students: A randomized controlled trial. Clin. Nutr. Res. 3:98-105.

Lee, K.-H., J.-L. Song, E.-S. Park, J. Ju, H.-Y. Kim, and K.-Y. Park. 2015. Anti-obesity effects of starter fermented Kimchi on 3T3-L1 adipocytes. Prev. Nutr. Food Sci. 20:298-302.

Lee, K. W., J. M. Shim, S.-K. Park, H.-J. Heo, H.-J. Kim, K.-S. Ham, and J. H. Kim. 2016. Isolation of lactic acid bacteria with probiotic potentials from kimchi, traditional Korean fermented vegetable. Lebensm. Wiss. Technol. 71:130-137.

Mao, X., C. Gu, H. Hu, J. Tang, D. Chen, B. Yu, and G. Tian. 2016. Dietary Lactobacillus rhamnosus GG supplementation improves the mucosal barrier function in the intestine of weaned piglets challenged by porcine rotavirus. PLoS One 11:e0146312.

Matsusaki, T., S. Takeda, M. Takeshita, Y. Arima, C. Tsend-Ayush, T. Oyunsuren, C. Sugita, H. Yoshida, W. Watanabe, and M. Kurokawa. 2016. Augmentation of T helper type 1 immune response through intestinal immunity in murine cutaneous herpes simplex virus type 1 infection by probiotic Lactobacillus plantarum strain 06CC2. Int. Immunopharmacol. 39:320-327.

Muhsen, K., G. Chodick, S. Goren, V. Shalev, and D. Cohen. 2010. The uptake of rotavirus vaccine and its effectiveness in preventing acute gastroenteritis in the community. Vaccine 29:91-94.

Mujagic, Z., P. De Vos, M. V. Boekschoten, C. Govers, H.-J. H. Pieters, N. J. De Wit, P. A. Bron, A. A. Masclee, and F. J. Troost. 2017. The effects of Lactobacillus plantarum on small intestinal barrier function and mucosal gene transcription; A randomized double-blind placebo controlled trial. Sci. Rep. 7:40128.

Nichols, C. A., J. Guezennec, and J. Bowman. 2005. Bacterial exopolysaccharides from extreme marine environments with special consideration of the southern ocean, sea ice, and deep-sea hydrothermal vents: A review. Mar. Biotechnol. (NY) 7:253-271. 
Patel, A., and J. Prajapat. 2013. Food and health applications of exopolysaccharides produced by lactic acid bacteria. J. Adv. Dairy Res. 1:1-8.

Patel, A., J. Prajapati, O. Holst, and A. Ljungh. 2014. Determining probiotic potential of exopolysaccharide producing lactic acid bacteria isolated from vegetables and traditional Indian fermented food products. Food Biosci. 5:27-33.

Patten, D. A., and A. P. Laws. 2015. Lactobacillus-produced exopolysaccharides and their potential health benefits: A review. Benef. Microbes 6:457-471.

Pott, J., T. Mahlakõiv, M. Mordstein, C. U. Duerr, T. Michiels, S. Stockinger, and M. W. Hornef. 2011. IFN- $\lambda$ determines the intestinal epithelial antiviral host defense. Proc. Natl. Acad. Sci. USA 108:7944-7949.

Reed, L. J., and H. Muench. 1938. A simple method of estimating fifty percent endpoints. Am. J. Hyg. 27:493-497.

Rollo, E. E., K. P. Kumar, N. C. Reich, J. Cohen, J. Angel, H. B. Greenberg, R. Sheth, J. Anderson, B. Oh, and S. J. Hempson. 1999. The epithelial cell response to rotavirus infection. J. Immunol. 163:4442-4452.

Ruas-Madiedo, P., J. Hugenholtz, and P. Zoon. 2002. An overview of the functionality of exopolysaccharides produced by lactic acid bacteria. Int. Dairy J. 12:163-171.

Shaw, R. D., S. J. Hempson, and E. R. Mackow. 1995. Rotavirus diarrhea is caused by nonreplicating viral particles. J. Virol. 69:59465950 .

Shin, R., Y. Itoh, M. Kataoka, S. Iino-Miura, R. Miura, T. Mizutani, and T. Fujisawa. 2016. Anti-tumor activity of heat-killed lactobacillus plantarum BF-LP284 on Meth-A tumor cells in BALB/c mice. Int. J. Food Sci. Nutr. 67:641-649.

Shornikova, A. V., I. A. Casas, E. Isolauri, H. Mykkänen, and T. Vesikari. 1997a. Lactobacillus reuteri as a therapeutic agent in acute diarrhea in young children. J. Pediatr. Gastroenterol. Nutr. 24:399-404.

Shornikova, A. V., I. A. Casas, H. Mykkanen, E. Salo, and T. Vesikari. 1997b. Bacteriotherapy with Lactobacillus reuteri in rotavirus gastroenteritis. Pediatr. Infect. Dis. J. 16:1103-1107.

Sindhu, K. N., T. V. Sowmyanarayanan, A. Paul, S. Babji, S. S. Ajjampur, S. Priyadarshini, R. Sarkar, K. Balasubramanian, C. A Wanke, and H. D. Ward. 2014. Immune response and intestinal permeability in children with acute gastroenteritis treated with Lactobacillus rhamnosus GG: A randomized, double-blind, placebo-controlled trial. Clin. Infect. Dis. 58:1107-1115.

Tam, K. I., and M. R. Roner. 2011. Characterization of in vivo antirotavirus activities of saponin extracts from Quillaja saponaria Molina. Antiviral Res. 90:231-241

Tanganurat, W., B. Quinquis, V. Leelawatcharamas, and A. Bolotin. 2009. Genotypic and phenotypic characterization of Lactobacillus plantarum strains isolated from Thai fermented fruits and vegetables. J. Basic Microbiol. 49:377-385.

Tate, J. E., A. H. Burton, C. Boschi-Pinto, U. D. Parashar, and World Health Organization-Coordinated Global Rotavirus Surveillance
Network. 2016. Global, regional, and national estimates of rotavirus mortality in children $<5$ years of age, 2000-2013. Clin. Infect. Dis. 62:S96-S105.

Tate, J. E., A. H. Burton, C. Boschi-Pinto, A. D. Steele, J. Duque, U. D. Parashar, and MBBS the WHO-coordinated Global Rotavirus Surveillance Network. 2012. 2008 estimate of worldwide rotavirusassociated mortality in children younger than 5 years before the introduction of universal rotavirus vaccination programmes: A systematic review and meta-analysis. Lancet Infect. Dis. 12:136-141.

Than, V. T., S. Jeong, and W. Kim. 2015. Characterization of RotaTeq ${ }^{\circledR}$ vaccine-derived rotaviruses in South Korean infants with rotavirus gastroenteritis. J. Med. Virol. 87:112-116.

Toshimitsu, T., S. Ozaki, J. Mochizuki, K. Furuichi, and Y. Asami. 2017. Effects of Lactobacillus plantarum strain OLL2712 culture conditions on the anti-inflammatory activities for murine immune cells and obese and type 2 diabetic mice. Appl. Environ. Microbiol. 83:e03001-e03016.

Velázquez, R. F., A. C. Linhares, S. Muñoz, P. Seron, P. Lorca, R. DeAntonio, and E. Ortega-Barria. 2017. Efficacy, safety and effectiveness of licensed rotavirus vaccines: A systematic review and meta-analysis for Latin America and the Caribbean. BMC Pediatr. 17:14

Ward, R. L., M. M. McNeal, and J. F. Sheridan. 1990. Development of an adult mouse model for studies on protection against rotavirus. J. Virol. 64:5070-5075.

Weninger, W., and U. H. von Andrian. 2003. Chemokine regulation of narve $\mathrm{T}$ cell traffic in health and disease. Semin. Immunol. $15: 257-270$.

Xing, J., G. Wang, Q. Zhang, X. Liu, Z. Gu, H. Zhang, Y. Q. Chen, and W. Chen. 2015. Determining antioxidant activities of lactobacilli cell-free supernatants by cellular antioxidant assay: A comparison with traditional methods. PLoS One 10:e0119058.

Yamamoto, Y., M. Kurachi, K. Yamaguchi, and T. Oda. 2007. Induction of multiple cytokine secretion from RAW264. 7 cells by alginate oligosaccharides. Biosci. Biotechnol. Biochem. 71:238-241.

Yang, W.-T., G.-L. Yang, S.-H. Shi, Y.-Y. Liu, H.-B. Huang, Y.-L. Jiang, J.-Z. Wang, C.-W. Shi, Y.-B. Jing, and C.-F. Wang. 2017. Protection of chickens against H9N2 avian influenza virus challenge with recombinant Lactobacillus plantarum expressing conserved antigens. Appl. Microbiol. Biotechnol. 101:4593-4603.

Zhang, L., N. Li, R. Caicedo, and J. Neu. 2005. Alive and dead Lactobacillus rhamnosus GG decrease tumor necrosis factor-alpha-induced interleukin-8 production in Caco-2 cells. J. Nutr. 135:1752-1756.

Zhang, L., C. Liu, D. Li, Y. Zhao, X. Zhang, X. Zeng, Z. Yang, and S. Li. 2013. Antioxidant activity of an exopolysaccharide isolated from Lactobacillus plantarum C88. Int. J. Biol. Macromol. 54:270275.

Zhang, X., Y. Kang, Z. Xie, J. Su, and X. Kong. 2016. Oral administration of Lactobacillus acidophilus stain SW1 suppresses tumor necrosis factor (TNF)-alpha and increases transforming growth factor (TGF)-beta in mice. Int. J. Clin. Exp. Med. 9:23461-23466. 